ISSN No: 2456 - 6470 | Volume - 3 | Issue - 1 | Nov - Dec 2018

\title{
Removal of Hexavalent Chromium by using Citric Acid Modified Tamarind Pod Shell Powder (Tamarindus Indica L.)
}

\author{
Jagruti S. Vaza, Satish A. Bhalerao \\ Environmental Sciences Research Laboratory, Department of Botany, \\ Wilson College, Mumbai, Maharashtra, India
}

\section{ABSTRACT}

Removal of the hexavalent chromium from aqueous solution was carried out using citric acid modified Tamarind pod shell powder (Tamarindus indica L.).The modified biosorbent was characterized by Fourier Transform Infrared (FTIR) spectroscopy, Scanning Electron Microscope (SEM) and X-ray diffraction (XRD) techniques. The effect of solution $\mathrm{pH}$, biosorbent dose, initial concentration of hexavalent chromium solution, contact time, temperature and agitation rate was investigated in a systematic manner. Experimental data were analyzed by kinetic parameters such as pseudo-first order and pseudo-second order models and found that the biosorption of hexavalent chromium onto biosorbent, followed pseudo-second order kinetic model by its good correlation coefficient value which is very close to the unity. The equilibrium data were analyzed by using Langmuir and Freundlich adsorption isotherm models. Among these adsorption isotherm models Langmuir model was fitted well with its good correlation coefficient and value. The results concluded that the modified Tamarind pod shell powder (Tamarindus indica L.) was an efficient, ecofriendly, and economically low cost biodsorbent which was used in the removal of hexavalent chromium from the aqueous medium.

Keywords: Tamarind pod shell powder (Tamarindus indica L.), hexavalent chromium, Batch study, Adsorption isotherms, Kinetics, Thermodynamic study

\section{INTRODUCTION:}

The pollution of water resources due to the disposal of heavy metals has been increasing worldwide and concern for the last few decades (Godea et al., 2007). Heavy metal contamination of soil is also one of the most important environmental problems throughout the world. The ability of heavy metals to accumulate and cause toxicity in biological systems - humans, animals, microorganisms and plants has been reported. As chemical hazards, heavy metals are nonbiodegradable and can remain almost indefinitely in the soil environment. Industrial activity is being growing in recent years and releases incomparable volume of waste in the environment and causing the major effect to the environment. Among these pollutants, heavy metals are considered as the major pollutants that can cause the dangerous effects to the environment and mankind (Seshadri et al., 2014). Toxic heavy metals contamination exists in aqueous waste streams through a variety of sources, such as mining, refining and electroplating (Kandah et al., 2008). As a consequence of several man-made factors such as unplanned urbanization, industrialization, deforestation etc. along with anthropogenic activities, there is a progressive increase in soil and water pollution by heavy metals such as arsenic, chromium, copper, lead, mercury, cadmium, nickel, zinc and iron etc. There are several methods for waste water treatment such as ion exchange, adsorption, chemical precipitation, oxidation, reduction and reverse osmosis. However, many of these processes can be less effective or difficult for practical use due to their high price and sludge disposal problem. Therefore, to minimize this problem, lot of investigations has been carried out by the researchers to find out low cost, easily available materials from agricultural waste along with industrial by-products as adsorbents. Experimental adsorption properties of numerous waste biomasses have been reported, such as- wheat bran, saw dust, sunflower stalk, spent grain, onion skin, rice husk, almond husk, modified barks, banana pills, rice milling by- products (hulls and brans) and soya bean hulls to remove heavy metals from waste 
water (Chowdhury et al., 2010). Several approaches have been studied and developed for the effective removal of $\mathrm{Cr}$ (VI) ion using biosorbents like peat, brown coal and humic acids, chitosan, hazelnut shell. (Erol Pehlivan et al., 2015). Many studies show removal and recovery of heavy metals with different biosorbents. Some industrial wastes and biological materials have shown potential in removing pollutants. Among those of biological origin with ability to adsorb dissolved metal ions (Joelington et al., 2014), there are the cactus (Dakiky et al., 2002), bagasse (Gupta et al., 2004), cyanobacterium (Gupta et al., 2008), green algae (Gupta et al., 2008), Oedogonium sp. and Nostoc sp. (Gupta et al., 2008), walnut shells (Altun et al., 2012), Osage orange (Pehlivan et al., 2012), Brown Seaweeds (Lee et al., 2012) and Moringa Oleifera (Rajeshwari et al., 2013) Plant material wastes and peels have been used intensively in bioremoving various heavy metal ions from industrial wastewater (Shartooh et al., 2013).

Chromium ions are amongst the heavy metal ions present in effluent of many chemical process industries. The toxicity of chromium depends on its oxidation state and water quality (Jain et al., 2015). The presence of $\mathrm{Cr}$ (VI) ions has become a major concern today due to its deleterious effects on health and environment (Khezami and Capart, 2005). Chromium is extensively used in pigments and paints, leather tanning, fungicides, electroplating, cement, steel, ceramic and glass industries (Kocaoba and Akcin, 2005). High levels of chromium in waste waters are a major concern around the world. Hexavalent chromium poses a greater health risk due to its carcinogenic activity and recently, trivalent chromium has also been associated with toxicity at higher concentrations (Sharma et al., 2007). Chromium $(\mathrm{Cr})$ is one of the important pollutants in surface water and groundwater. Chromium can be beneficial and toxic to living organism depending on its oxidation state and concentrations. $\mathrm{Cr}$ (VI) is more toxic than $\mathrm{Cr}$ (III) and it is better absorbed than $\mathrm{Cr}$ (III) for both acute and chronic exposures (Parlayici et al., 2012). The use of other alternative techniques (such as adsorption, ion exchange, membrane and biological processes) based on physical, chemical and biological mechanisms is advisable in order to protect the environment and at the same time recovering at least available metal ( $\mathrm{Hu}$ et al, 2003). As $\mathrm{Cr}$ (VI) is carcinogenic, a maximum permissible concentration for total Cr of $0.5 \mathrm{mg} / \mathrm{L}$ and for $\mathrm{Cr}$ (VI) of $0.05 \mathrm{mg} / \mathrm{L}$ is legally prescribed in wastewater after treatment
(Gao et al, 1999). Therefore, the control of the chromium level in wastewater is essential (Petruzzelli et al, 1996).

Biomaterials derived from agricultural waste have received much attention by researchers seeking to develop low-cost and efficient materials for adsorption of pollutants. Biomaterials have been used for the removal of various pollutants including dyes, lead, zinc, cadmium. Such waste materials are basically made up of lignin, cellulose and hemicellulose which usually account for exchange and complexation properties of this class of adsorbents. Although these adsorbents have shown promising results for the removal of pollutants from wastewater, there are still limitations encountered in their use including their low uptake capacity when used in the raw form and the release of organic components leading to a high chemical and biological oxygen demand and total organic carbon. To overcome these limitations, lignocellulosic materials are usually chemically activated to improve their properties and performance using several types of chemical reagents including basic solutions such as sodium hydroxide, calcium hydroxide and sodium carbonate and inorganic acid solutions such as hydrochloric acid, nitric acid, sulfuric acid, tartaric acid, citric acid and thioglycollic acid. Chemical treatment of biomaterials does not only aid the extraction of soluble organic compounds from lignocellulosic materials thereby enhancing chelating efficiency, but also modifies the surface chemical properties of the final product (Pakade et al., 2017)

In India, tamarind (Tamarindus indica L.) is an economically important tree which grows abundantly in the dry tracts of Central and South Indian States. Indian production of tamarind is about 3 lakh $(0.3$ million) tonnes per year. The hard pod shell is removed (deshelled) when the fruit is ripe and the fruit is the chief acidulant used in the preparation of foods. The shells are discarded as waste and since it is available free of cost, only the transport cost is involved for hauling it from the point of generation for wastewater treatment. Hence, recycling of this waste for wastewater treatment would not only be economical but also help to solve waste disposal problems (Ahalya et al., 2008).

Thus, this work uses Tamarind pod shell powder modified with citric acid (CA) for $\mathrm{Cr}$ (VI) removal from aqueous solutions. Operational parameters such 
as the influence of $\mathrm{pH}$, amount of biosorbent, initial concentration in chromium (VI), contact time and agitation rate for chromium (VI) removal have been investigated. Applicability of adsorption model, kinetic study and thermodynamic study in the sorption process was also investigated.

\section{MATERIAL AND METHODS: Chemical and reagent:}

All the chemicals and reagents used were of analytical reagent (AR) grade. Double distilled water was used for all experimental work including the preparation of metal solutions. The desired $\mathrm{pH}$ of the metal ion solution was adjusted with the help of dilute hydrochloric acid and sodium hydroxide.

\section{Preparation of Chromium (VI) solution:}

The stock solution of 1000 ppm of chromium (VI) was prepared by dissolving $0.7072 \mathrm{~g}$ of potassium dichromate $\left(\mathrm{K}_{2} \mathrm{Cr}_{2} \mathrm{O}_{7}\right)$ (AR grade) (previously dried at $50^{\circ} \mathrm{C}$ for one hour) in $250 \mathrm{ml}$ of double distilled water and further desired test solutions of chromium (VI) were prepared using appropriate subsequent dilutions of the stock solution.

\section{Preparation of biosorbent:}

The tamarind pod shells (Tamarindus indica L.) were collected from local market. The collected Tamarind pod shells were washed with several times with distilled water to remove the surface adhered particles, dirt and other unwanted material \& water soluble impurities. Biosorbent was then dried in the sunlight for three days. The dried pieces were ground in a steel mill to get a fine powder and it was sieved to select particles $100 \mu \mathrm{m}$ in size will be used in all the experiments. The final product was named as tamarind pod shell (Tamarindus indica L.) powder. For further use, the dried biosorbent was stored in air tighten plastic bottle to protect it from moisture.

\section{Preparation of citric acid modified tamarind pod} shell (Tamarindus indica L.):

About $25 \mathrm{~g}$ grinded tamarind pod shell powder was mixed with $17.5 \mathrm{~cm}^{3}$ of $1.2 \mathrm{M}$ citric acid (CA). The mixture was stirred until homogenous and dried at $60^{\circ} \mathrm{C}$ in oven for 24 hours. Again it was kept in oven at $120^{\circ} \mathrm{C}$ for 2 hours. The treated tamarind pod shell powder was subsequently washed with distilled water and dried for 40 hours in oven at $50^{\circ} \mathrm{C}$. The final product was labelled as citric acid modified tamarind pod shell (Tamarindus indica L.).

\section{Instrumentation:}

The $\mathrm{pH}$ of the solution was measured by digital $\mathrm{pH}$ meter (EQUIP-TRONICS, model no. Eq-610) using a combined glass electrode. The concentration of chromium (VI) in the solutions before and after equilibrium was determined by using Inductively Coupled Plasma-Atomic Emission Spectroscopy (ICP-AES) technique. Biosorbent was characterized by Fourier Transform Infrared (FTIR), Scanning Electron Microscope (SEM) and X-ray diffraction (XRD).

\section{Characterization of biosorbent by Fourier} Transform Infrared (FTIR) analysis:

The Fourier Transform Infrared (FTIR) spectroscopy was used to identify the functional groups present in the biosorbent. The biomass samples were examined using FTIR spectrometer (model:FT/IR-4100typeA) within range of $400-4000 \mathrm{~cm}-1$. All analysis was performed using $\mathrm{KBr}$ as back ground material. In order to form pellets, $0.02 \mathrm{~g}$ of biomass was mixed with $0.3 \mathrm{~g} \mathrm{KBr}$ and pressed by applying pressure.

\section{Characterization of biosorbent by Scanning} Electron Microscope (SEM) analysis:

The Scanning Electron Microscope (SEM) was used to see the porosity of the biosorbent. The samples were covered with a thin layer of gold and an electron acceleration voltage of $10 \mathrm{KV}$ was applied and then Scanning Electron Micrograph was recorded.

\section{Characterization of biosorbent by X-ray diffraction (XRD) analysis:}

$\mathrm{X}$-ray diffraction (XRD) was used for the qualitative and quantitative determination of solid samples of biosorbent. It works on the principle that X-ray diffraction pattern is unique for each sample. This pattern from XRD was compared with a known compound and the chemical compound was identified.

\section{Experimental procedure:}

The batch method was employed at room temperature to examine the biosorption of chromium (VI) by biosorbent. The method was used to determine the adsorption capacity, stability of biosorbent and optimum biosorption conditions. The parameters were studied by combining biosorbent with chromium (VI) solution in $250 \mathrm{ml}$ separate reagent bottles. The reagent bottles were placed on a shaker with a constant speed and left to equilibrate. The samples were collected at predefined time intervals, 
centrifuged, the content was separated from the adsorbent by filtration, using Whatman filter paper and amount of chromium (VI) in the filtrate solutions was determined by ICP-AES. The following equation was used to compute the percent removal (\% Adsorption) of chromium (VI) by the adsorbent,

$$
\% \mathrm{Ad}=\frac{\left(\mathrm{C}_{\mathrm{i}}-\mathrm{C}_{\mathrm{e}}\right)}{\mathrm{C}_{\mathrm{i}}} \times 100 \text { (1) }
$$

Where $C i$ and $C e$ are the initial concentrations and equilibrium concentrations of the chromium (VI) in $\mathrm{mg} / \mathrm{L}$. The equilibrium adsorptive quantity (qe) was determined by the following equation,

$$
\boldsymbol{q}_{e}=\frac{\left(C_{i}-C_{e}\right)}{w} \times V
$$

Where qe (mg metal per g dry biosorbent) is the amount of chromium (VI) biosorbed, V (in liter) is the solution volume and w (in gram) is the amount of dry biosorbent used.

\section{Desorption Study:}

To evaluate desorption efficiency, chromium (VI) loaded biosorbent was dried after equilibrium sorption experiments. The dried biosorbent was contacted with $0.1 \mathrm{M}$ nitric acid $\left(\mathrm{HNO}_{3}\right), 0.1 \mathrm{M}$ hydrochloric acid $(\mathrm{HCl})$ and $0.1 \mathrm{M}$ sulphuric acid $\left(\mathrm{H}_{2} \mathrm{SO}_{4}\right)$ separately for 3 hours to allow chromium (VI) to be release from biosorbent. The samples were separated from the biosorbents by filtration, using Whitman filter paper and amount of chromium (VI) in the filtrate solutions was determined by ICP-AES to find out desorption efficiency. Desorption efficiency was calculated from the amount of metal adsorbed on the biosorbent and the final metal concentration in the biosorption medium.

$$
\text { Desorption efficiency }(\%)=\frac{\text { released metal ions in } \mathrm{mg} / \mathrm{L}}{\text { initially adsorbed metal ions in } \mathrm{mg} / \mathrm{L}} \times 100
$$

\section{RESULT AND DISCUSSION}

\section{Characterization of bio sorbent by Fourier} Transform Infrared (FTIR) analysis:

The Fourier Transform Infrared (FTIR) spectroscopy was used to identify the functional groups present in the bio sorbent. The bio sorbent samples were examined using FTIR spectrometer within range of $400-4000 \mathrm{~cm}^{-1}$. All analysis was performed using $\mathrm{KBr}$ as back ground material. In order to form pellets, $0.02 \mathrm{~g}$ of biomass was mixed with $0.3 \mathrm{~g} \mathrm{KBr}$ and pressed by applying pressure. To investigate the functional groups of bio sorbent and metal loaded with bio sorbent, a FTIR analysis was carried out and the spectra are shown in Fig.1. ( $a$ and b). As seen in the figure unloaded bio sorbent displays a number of absorption peaks, reflecting the complex nature of bio sorbent. The broad peak at $3330 \mathrm{~cm}^{-1}$ is the indicator of $-\mathrm{OH}$ and $\mathrm{NH}$ groups. The peaks located at $1736 \mathrm{~cm}^{-1}$ are characteristics of carbonyl group. The presence of $\mathrm{OH}$ group along with carbonyl group confirms the presence of carboxyl acid groups in the bio sorbent. The peaks observed at $1030 \mathrm{~cm}^{-1}$ are due to $\mathrm{C}-\mathrm{H}$ and $\mathrm{C}-\mathrm{O}$ bonds. The $-\mathrm{OH}, \mathrm{NH}$, carbonyl and carboxyl groups are important sorption sites. As compared to simple bio sorbent, bio sorbent loaded with chromium (VI) the broadening of $-\mathrm{OH}$ peak at $3463 \mathrm{~cm}^{-1}$ and carbonyl group peak at $1638 \mathrm{~cm}^{-1}$ was observed. This indicates the involvement of hydroxyl and carbonyl groups in the biosorption of chromium (VI).

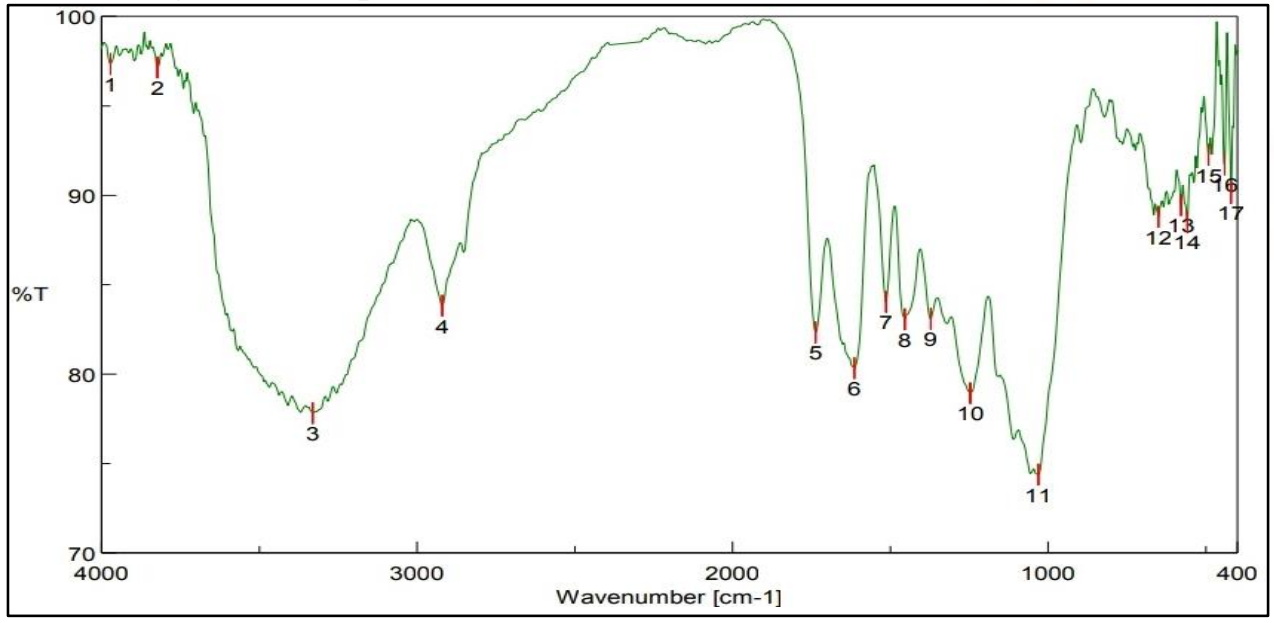

(a) 


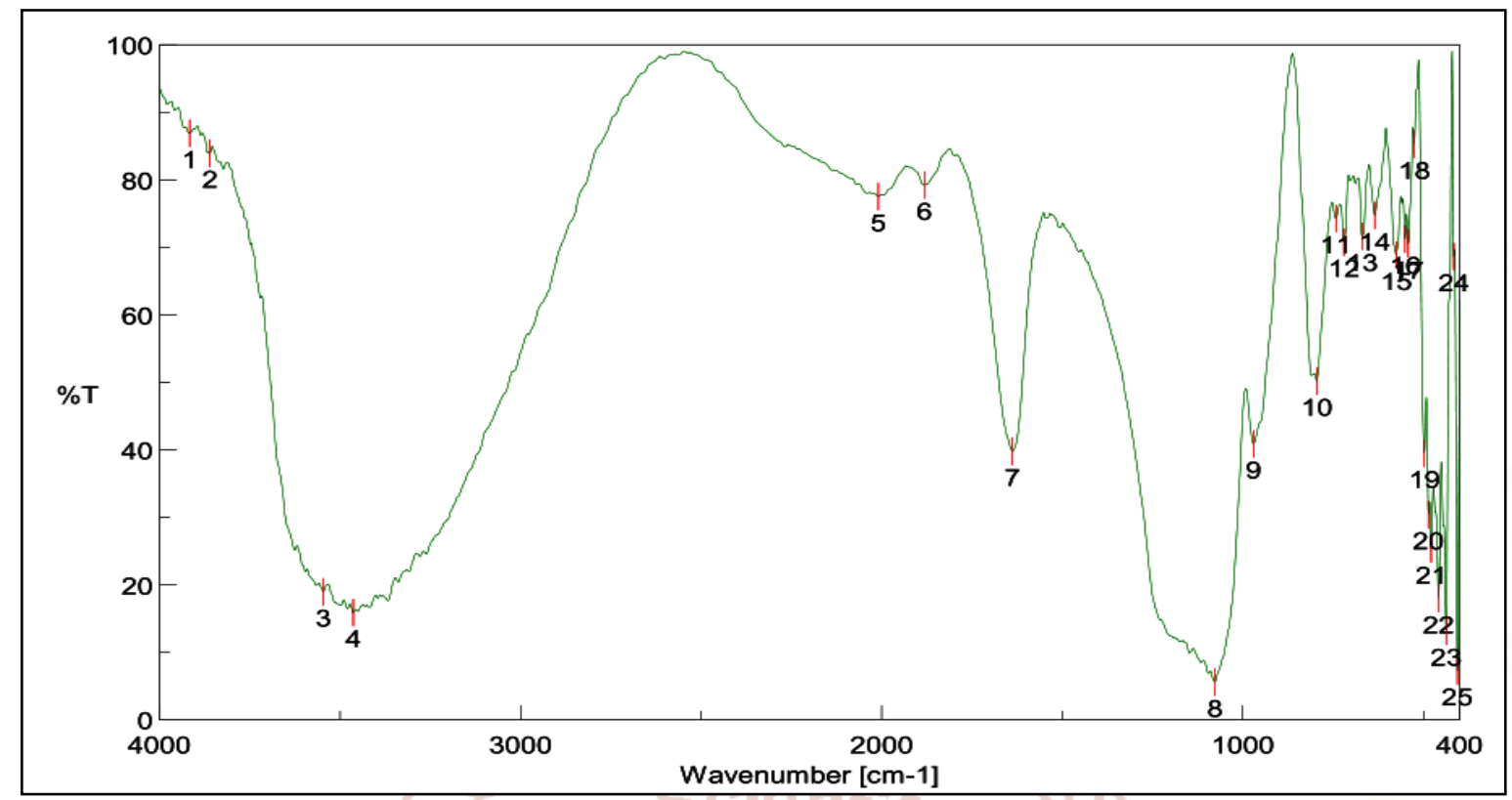

(b)

Figure 1: FTIR spectra of citric acid modified tamarind pod shell (Tamarindus indica L.)(a) Unloaded with chromium (VI) (b) Loaded with chromium (VI)

\section{Characterization of bio sorbent by Scanning} Electron Microscope (SEM) analysis:

Scanning Electron Microscope (SEM) analysis was carried out for the biosorption of chromium (VI) on the surfaces of the citric acid modified tamarind pod shell (Tamarindus indica L.). The SEM images of citric acid modified tamarind pod shell (Tamarindus indica $\mathrm{L}$.) before and after biosorption of chromium (VI) are shown in Figure 2 (a) and 2 (b) respectively.

there is more uniformity after biosorption of chromium (VI) onto biosorbent in comparison to before biosorption. It was evident from the mictrographs that the biosorbents presents an unequal structure before chromium (VI) adsorbed. The number of canals in the biosorbents was higher in the initial case. The chromium (VI) adsorbed on the cell wall matrix and created stronger cross linking and uniformity on the surface of biosorbent. large surface area. The SEM clearly demonstrated that

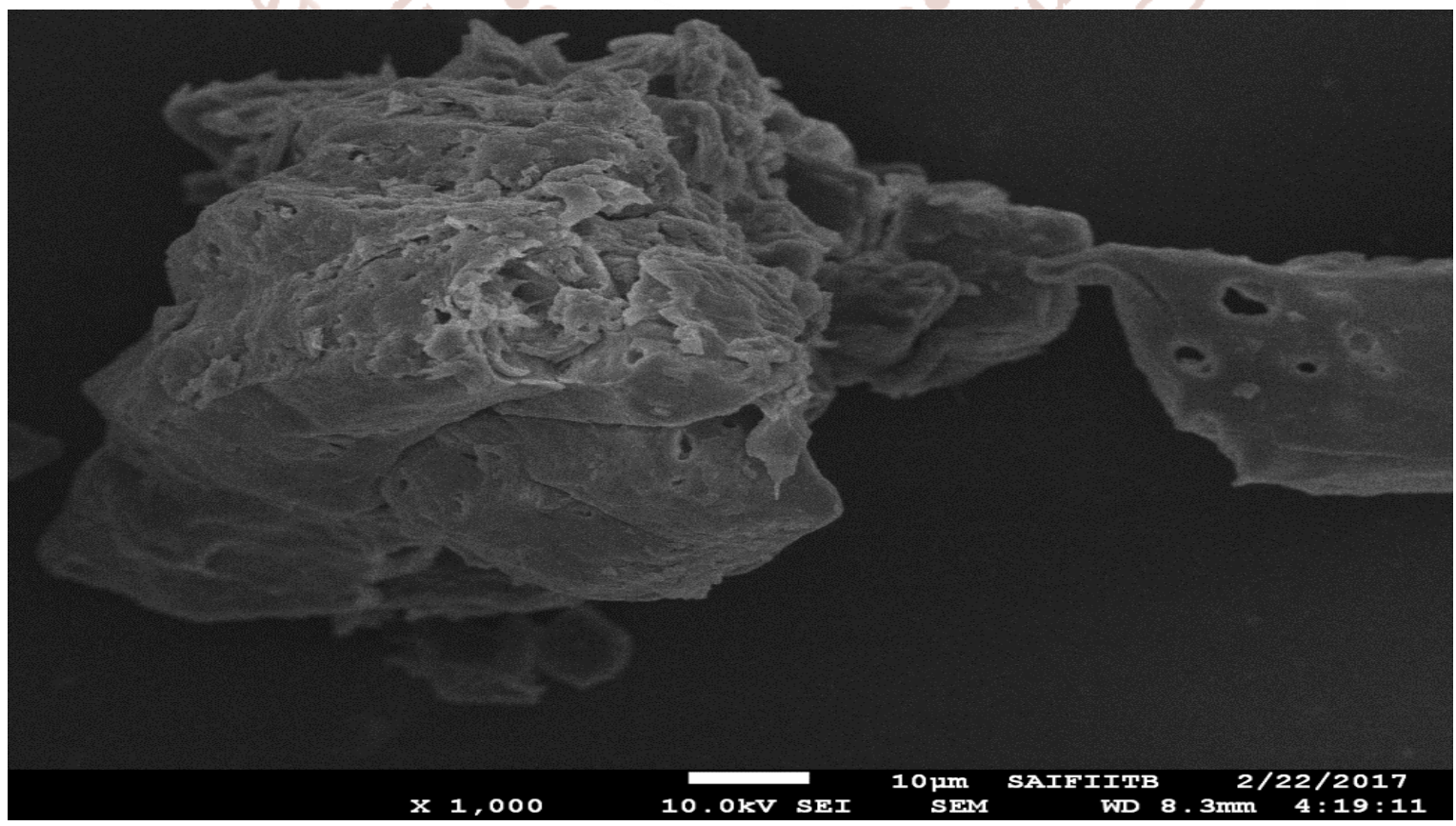

(a) 


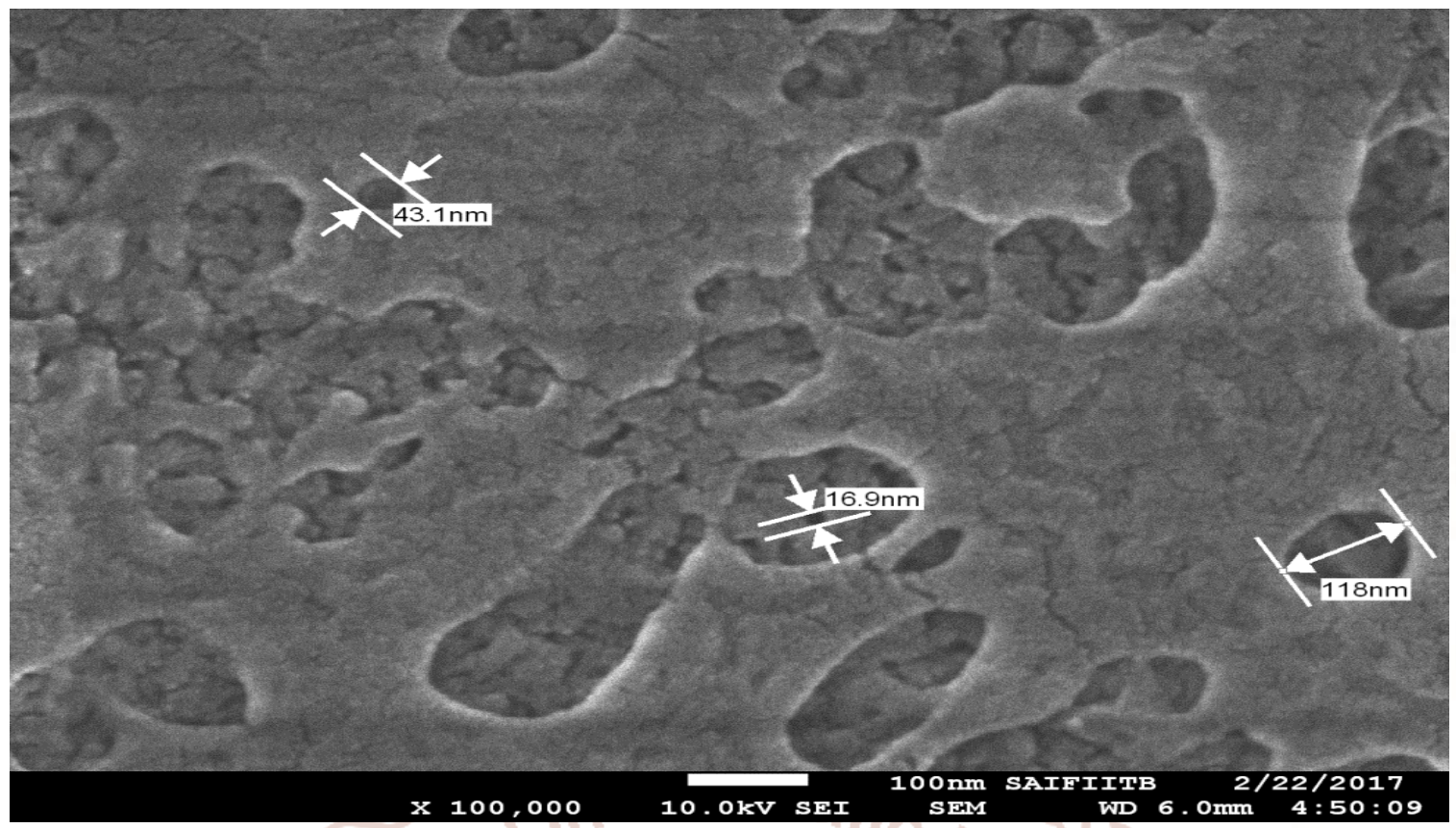

(b)

Figure 2: Scanning Electron Microscope (SEM) analysis of citric acid modified tamarind pod shell

(Tamarindus indica L.) (a) Unloaded with chromium (VI) (b) Loaded with chromium (VI)

X-ray diffraction analysis (XRD) analysis:

XRD pattern of the unloaded and loaded biosorbent with the chromium (VI) solution is shown in Figure 3(a) and 3(b). The XRD spectra of unloaded chromium (VI) which shows broad peaks were obtained instead of sharp peaks indicating the sample was poorly crystalline. The XRD spectra of loaded chromium (VI) exhibit strong peaks at $2 \theta$ value $24^{\circ}$ and $45.76^{\circ}$ equivalent to 240.049 and 163.0769 respectively

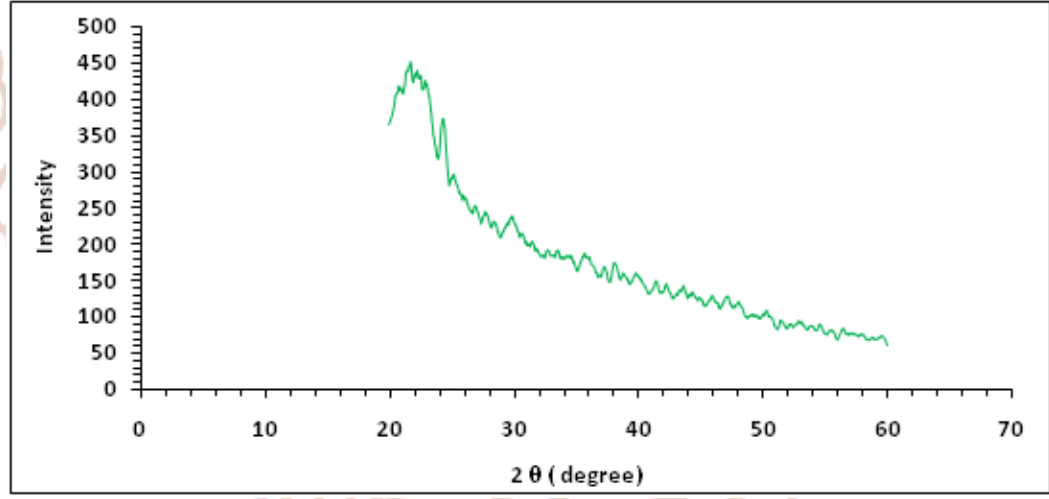

(a)

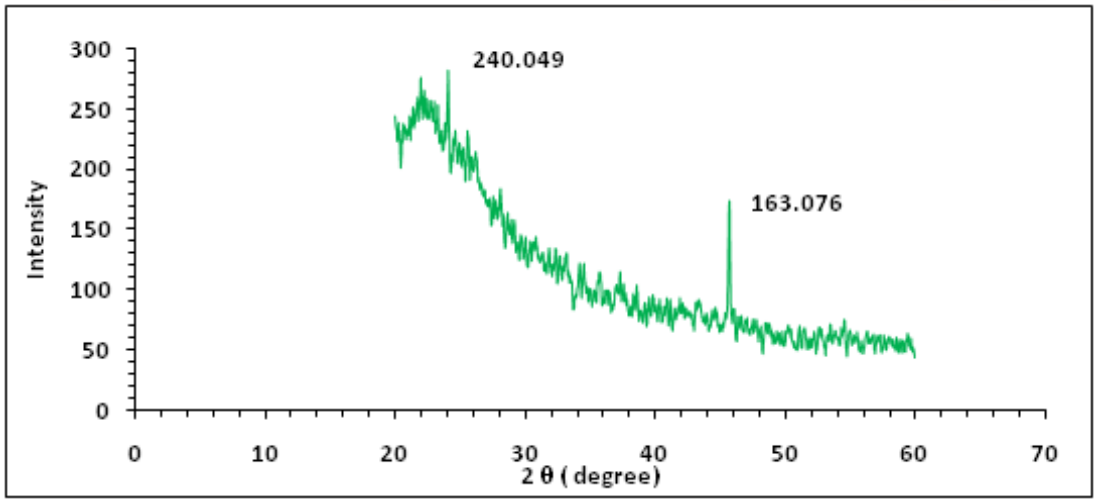

(b)

Figure 3:X-ray diffraction (XRD) analysis of citric acid modified tamarind pod shell (Tamarindus indica L.)(a) Unloaded with chromium (VI) (b) Loaded with chromium (VI) 


\section{Effect of pH}

Figure 4 shows the effect of $\mathrm{pH}$ of the solution on the removal of chromium (VI). The $\mathrm{pH}$ of the solution is an important variable which controls the adsorption. Hence, the influence of $\mathrm{pH}$ on the adsorption of Chromium (VI) ions onto citric acid modified tamarind pod shell powder was examined in the $\mathrm{pH}$ range of 1 to 8 . The adsorption capacities of chromium (VI) ions onto citric acid modified tamarind pod shell powder increased significantly, with decreasing $\mathrm{pH}$ value and the maximum removal was attained at $\mathrm{pH}$ 4.0. It was found that at $\mathrm{pH} 4$ the biosorption process was maximum with $93.01 \%$ and after increasing $\mathrm{pH}$, biosorption was decreases. At lower $\mathrm{pH}$, the $\mathrm{Cr}(\mathrm{VI})$ removal efficiency was higher and at higher $\mathrm{pH}$ the removal reduced considerably. The $\mathrm{Cr}(\mathrm{V})$ exists in different forms such as $\mathrm{HCrO}^{4-}$, $\mathrm{Cr}_{2} \mathrm{O}_{7}{ }^{2-}$ and $\mathrm{CrO}^{-4}$ in aqueous solution and stability of these forms is dependent on the $\mathrm{pH}$ of the system. The active form of $\mathrm{Cr}(\mathrm{VI})$ adsorbed is $\mathrm{HCrO}^{4-}(\mathrm{Rao}$ et al., 1992). This form is stable at only lower $\mathrm{pH}$ range which leads to high removal of chromium. But the concentration of this form decreases with the increase of $\mathrm{pH}$.

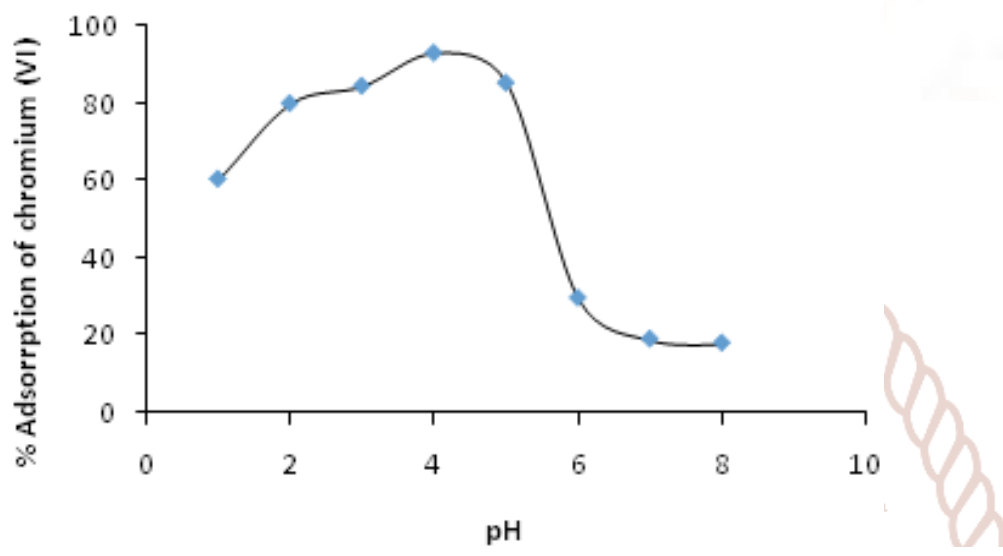

Figure 4: Effect of pH on chromium (VI) biosorption by citric acid modified tamarind pod shell (Tamarindus indica L.) (Bio sorbent dose concentration: $5 \mathrm{~g} / \mathrm{L}$, chromium (VI) concentration: $10 \mathrm{mg} / \mathrm{L}$, contact time: 180 minutes, agitation rate: $120 \mathrm{rpm}$, temperature: $40^{\circ} \mathrm{C}$ )

\section{Effect of the biodsorbent dose concentration:}

Biosorbent dose is an important parameter for the determination of the biosorption capacity of citric acid treated tamarind pod shell (Tamarindus indica L.). The effect of biosorbent dose on the percentage removal of chromium (VI) increases very sharply with the increase in biosorbent dose but beyond 0.5 $\mathrm{g} / \mathrm{l}$ the percentage removal decreases. The maximum biosorption efficiency of chromium (VI) ion onto citric acid treated tamarind pod shell (Tamarindus indica L.) was found to be $92.85 \%$ at the dose of 0.5 g. The increase in removal efficiency of chromium (VI) ions from aqueous solutions can be attributed to the increased number of sites and exchangeable sites available for adsorption (Naiya et al., 2009). The decrease in efficiency at higher biosorbent concentration could be explained as a consequence of partial aggregation of adsorbent which results in a decrease in effective surface area for metal uptake (Karthikeyan et al., 2007). Hence, biosorbent dose 5 $\mathrm{g} / \mathrm{L}$ was chosen for all further studies.

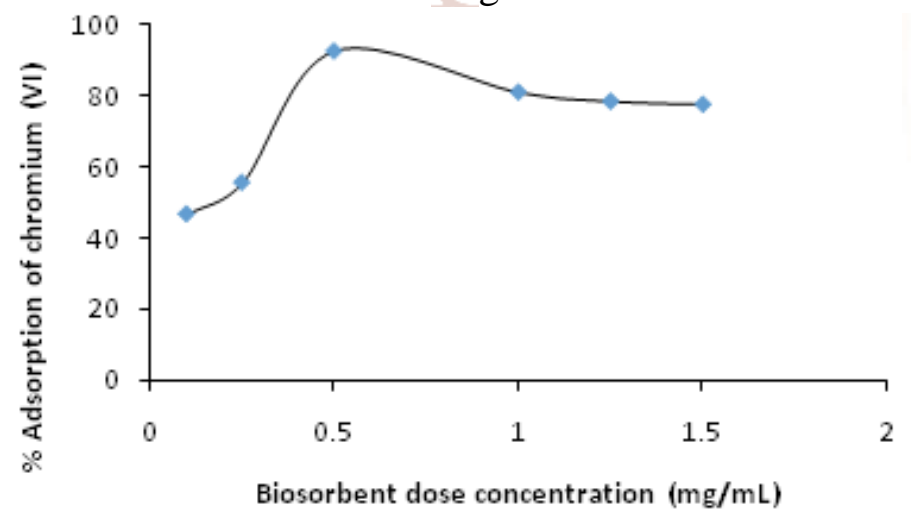

Figure 5: Effect of bio sorbent dose concentration on chromium (VI) biosorption by citric acid modified tamarind pod shell (Tamarindus indica $\mathrm{L}$.) (pH: 4, chromium (VI) concentration: $10 \mathrm{mg} / \mathrm{L}$, contact time: 180 minutes, agitation rate: $120 \mathrm{rpm}$, temperature: $40^{\circ} \mathrm{C}$ ) 


\section{Effect of initial chromium (VI) concentration}

Figure 6 shows the effect of initial concentration of chromium (VI) on the adsorption of chromium (VI) by Tamarind pod shell powder. The result revealed that almost $93.01 \%$ of chromium (VI) removal was achieved at low concentrations $(10-100 \mathrm{mg} / \mathrm{L})$. When the concentration was increased from 100 to 300 $\mathrm{mg} / \mathrm{L}$, the percent removal of chromium (VI) decreased, while adsorption capacities increased with decrease in concentration. The decrease in adsorption of chromium (VI) at high concentration was due to the saturation of active binding sites (Basal et al., 2009; Gupta and Rastogi 2009).

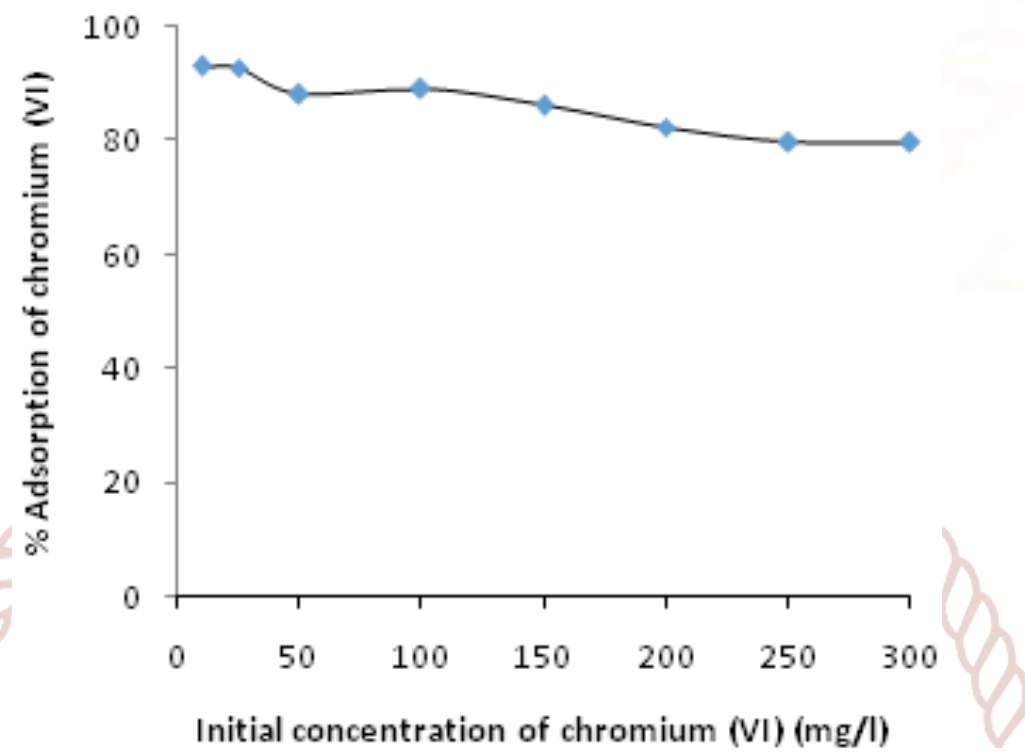

Figure 6: Effect of chromium (VI) concentration on chromium (VI) biosorption by citric acid modified tamarind pod shell (Tamarindus indica L.) (pH: 4, bio sorbent dose concentration: 5 g/L, contact time: 180 minutes, agitation rate: $120 \mathrm{rpm}$, temperature: $40^{\circ} \mathrm{C}$ )

\section{Effect of contact time}

Figure 7 shows the adsorption capacity of citric acid treated tamarind pod shell (Tamarindus indica L.) as a function of time. Contact time was varied from 10 to $240 \mathrm{~min}$. It was observed that the uptake of chromium (VI) was increases by increases time of shaking. After $180 \mathrm{~min}$ reached equilibrium for adsorption, suggesting that optimum removal was achieved at 180 min. Therefore, $180 \mathrm{~min}$ was used in subsequent experiments. The longer equilibration time (180 min) attained was attributable to the materials having deeper embedded adsorption sites that were not easily accessible or that the surface of the materials was slightly hydrophobic causing repulsion of chromium (VI)

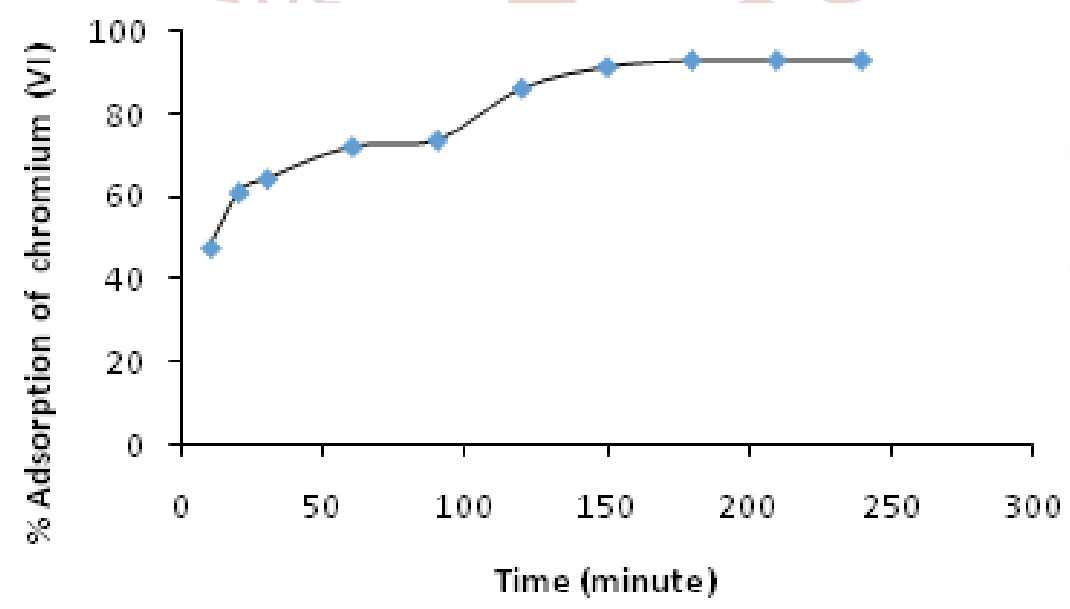

Figure 7: Effect of contact time on chromium (VI) biosorption by citric acid modified tamarind pod shell (Tamarindus indica L.) (pH: 4, bio sorbent dose concentration: $5 \mathrm{~g} / \mathrm{L}$, initial chromium (VI) concentration: $10 \mathrm{mg} / \mathrm{ml}$, agitation rate: $120 \mathrm{rpm}$ temperature: $40^{\circ} \mathrm{C}$ ) 


\section{Effect of temperature:}

The effect of temperature on removal of chromium (VI) from aqueous solutions using citric acid modified tamarind pod shell was studied at different temperatures from $20^{\circ} \mathrm{C}-40^{\circ} \mathrm{C}$. The influence of temperature is depicted in Figure 8. The percentage removal of chromium (VI) increased from $74.18 \%$ to

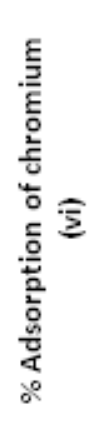

$93.18 \%$ in the range of temperature $20-40^{\circ} \mathrm{C}$ respectively. It can be clearly seen from the figure that, increase in temperature the percentage removal increased slowly. The increase in biosorption capacity with the increase in temperature indicates that the biosorption process is endothermic in nature.

\section{Figure 8: Effect of temperature on chromium (VI) biosorption by citric acid modified tamarind pod shell (Tamarindus indica $\mathrm{L}$.) (pH 4, bio sorbent dose concentration: $5 \mathrm{~g} / \mathrm{L}$, initial chromium (VI) ions concentration: $10 \mathrm{mg} / \mathrm{L}$, agitation rate: $120 \mathrm{rpm}$, contact time: 180 minutes)}

\section{Agitation rate:}

Figure 9 shows the effect of agitation rate on the increasing agitation rate decreases the film resistance adsorption of chromium (VI). It was varied from 40 to 1 to mass transfer surrounding the sorbent particles. The $200 \mathrm{rpm}$. The agitation rate increased from 80-120 percentage removal of chromium (VI) was maximum rpm then decreases. The result suggests that at $120 \mathrm{rpm}(93.11 \%)$.

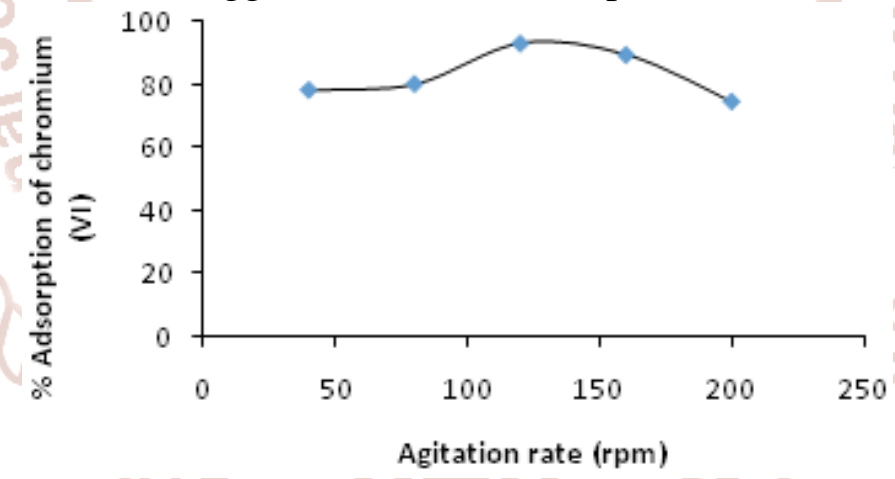

Figure 9: Effect of agitation rate on chromium (VI) biosorption by citric acid modified tamarind pod shell (pH 4, bio sorbent dose concentration: $5 \mathrm{~g} / \mathrm{L}$, initial chromium (VI) ions concentration: $10 \mathrm{mg} / \mathrm{L}$, contact time: 180 minutes, temperature: $40^{\circ} \mathrm{C}$ )

\section{Desorption study:}

In application of real wastewater, desorption of heavy metal ions in the bio sorbent is important process. Citric acid modified tamarind pod shell (Tamarindus indica $L$.) was the most effective waste bio sorbent with desorption efficiency $56.60 \% \quad(0.1 \quad \mathrm{M}$ hydrochloric acid), $74.29 \%$ (0.1 M nitric acid) and $85.17 \%$ (0.1 M sulphuric acid). Sulphuric acid has shown highest desorbed capacity of chromium (VI) followed by hydrochloric acid and nitric acid from citric acid modified tamarind pod shell (Tamarindus indica $L$.).

\section{Adsorption isotherms:}

The analysis of the adsorption isotherms data by fitting them into different adsorption isotherm models is an important step to find the suitable model that can be used for design process. The experimental data were applied to the two-parameter adsorption isotherm models: Langmuir, Freundlich, DubininKaganer-Redushkevich (DKR) and Temkin. Adsorption isotherms results for biosorption of chromium (VI) by citric acid modified tamarind pod shell (Tamarindus indica L.) are shown below; 
Langmuir adsorption isotherm (Langmuir, 1918): The Langmuir equation, which is valid for monolayer sorption onto a surface of finite number of identical sites, is given by;

$$
\mathrm{q}_{\mathrm{e}}=\frac{\mathrm{q}_{\mathrm{m}} \mathrm{b} \mathrm{C}_{\mathrm{e}}}{1+\mathrm{bC}_{\mathrm{e}}}
$$

Where $\mathrm{q}_{\mathrm{m}}$ is the maximum biosorption capacity of adsorbent $\left(\mathrm{mg} \mathrm{g}^{-1}\right) . \mathrm{b}$ is the Langmuir biosorption constant $\left(\mathrm{L} \mathrm{mg}^{-1}\right)$ related to the affinity between the bio sorbent and biosorbate. Linearized Langmuir isotherm allows the calculation of adsorprtion capacities and Langmuir constants and is represented as:

$$
\frac{1}{q_{e}}=\frac{1}{q_{m} b C_{e}}+\frac{1}{q_{m}}
$$

The linear plots of $1 / \mathrm{q}$ vs $1 / \mathrm{c}_{\mathrm{e}}$ is shown in Figure 10 (a). The two constants $b$ and $q_{m}$ are calculated from the slope $\left(1 / \mathrm{q}_{\mathrm{m}} \cdot \mathrm{b}\right)$ and intercept $\left(1 / \mathrm{q}_{\mathrm{m}}\right)$ of the line. The values of $\mathrm{q}_{\mathrm{m}}, \mathrm{b}$ and regression coefficient $\left(\mathrm{R}^{2}\right)$ are listed in Table 1.

The essential characteristics of the Langmuir isotherm parameters can be used to predict the affinity between the biosorbate and bio sorbent which is calculated using following equation;

$$
\boldsymbol{R}_{\boldsymbol{L}}=\frac{1}{1+b c_{\mathrm{i}}}
$$

Where $b$ is the Langmuir constant and $C_{i}$ is the maximum initial concentration of chromium (VI). The value of separation parameters $R_{L}$ provides important information about the nature of adsorption. The value of $R_{L}$ indicated the type of Langmuir isotherm separation factor or dimensionless equilibrium parameters, $R_{L}$ expressed as in the following equation: to be irreversible $\left(R_{L}=0\right)$, favorable $\left(0<R_{L}<1\right)$, linear $\left(R_{L}=1\right)$ or unfavourable $\left(R_{L}>1\right)$. The $R_{L}$ was found to 0.6119-0.0499 for concentration of $10 \mathrm{mg} / \mathrm{L}$ to 300 $\mathrm{mg} / \mathrm{L}$ of chromium (VI). They are in the range of $0-1$ which indicates favourable biosorption.

Freundlich adsorption isotherm (Freundlich, 1906): Freundlich equation is represented by;

$$
\mathrm{qe}_{\mathrm{e}}=\mathrm{KC}_{\mathrm{e}} \mathrm{i}^{1 / \mathrm{n}}
$$

Where $\mathrm{K}$ and $\mathrm{n}$ are empirical constants incorporating all parameters affecting the biosorption process suchas, biosorption capacity and biosorption intensity respectively.
Linearized Freundlich adsorption isotherm was used to evaluate the sorption data and is represented as:

$$
\log q_{e}=\log K+\frac{1}{n} \log C_{e}
$$

Equilibrium data for the adsorption is plotted as $\log \mathrm{q}$ vs $\log \mathrm{Ce}$, as shown in Figure 10 (b). The two constants $n$ and $K$ are calculated from the slope $(1 / n)$ and intercept $(\log K)$ of the line, respectively. The values of $K, 1 / \mathrm{n}$ and regression coefficient $\left(\mathrm{R}^{2}\right)$ are listed in Table 1.

The $\mathrm{n}$ value indicates the degree of non-linearity between solution concentration and adsorption as follows: if $\mathrm{n}=1$, then adsorption is linear; if $\mathrm{n}<1$, then adsorption is chemical process; if $n>1$, then adsorption is a physical process. A relatively slight slope and a small value of $1 / \mathrm{n}$ indicate that, the biosorption is good over entire range of concentration. The $\mathrm{n}$ value in Freundlich equation was found to be 1.4178. Since $n>1$, this indicates that biosorption is a physical process biosorption of chromium (VI) ions onto citric acid modified tamarind pod shell. The higher value of $K$ (2.7720) indicates the higher adsorption capacity for the citric acid modified tamarind pod shell (Tamarindus indica $\mathrm{L}$ ).

\section{Dubinin-Kaganer-Radushkevich(DKR) adsorption isotherm (Dubinin and Radushkevich, 1947):}

Linearized Dubinin-Kaganer-Radushkevich (DKR) adsorption isotherm equation is represented as;

$$
\ln q_{e}=\ln q_{m}-\beta \varepsilon^{2}
$$

Where $\mathrm{q}_{\mathrm{m}}$ is the maximum biosorption capacity, $\beta$ is the activity coefficient related to mean biosorption energy and $\varepsilon$ is the polanyi potential, which is calculated from the following relation;

$$
\varepsilon=R \operatorname{Tn}\left(1+\frac{1}{C e}\right)
$$

Equilibrium data for the adsorption is plotted as $\operatorname{lnq}_{\mathrm{e}}$ vs $\varepsilon^{2}$, as shown in Figure 10 (c). The two constants $\beta$ and $\mathrm{q}_{\mathrm{m}}$ are calculated from the slope $(\beta)$ and intercept $\left(\operatorname{lnq}_{\mathrm{m}}\right)$ of the line, respectively. The values of adsorption energy $\mathrm{E}$ was obtained by the following relationship,

$$
\mathrm{E}=\frac{1}{\sqrt{-2 \beta}}
$$

The E value was found to be $0.9129 \mathrm{KJ}$ mol- 1 . The mean free energy gives information about biosorption mechanism whether it is physical or chemical biosorption. If $\mathrm{E}$ value lies between $8 \mathrm{KJ}$ mol-1 and $16 \mathrm{KJ}$ mol-1, the biosorption process take place 
International Journal of Trend in Scientific Research and Development (IJTSRD) ISSN: 2456-6470

chemically and $\mathrm{E}>8 \mathrm{KJ}$ mol-1, the biosorption process of the physical in nature (Olivieri and Brittenham, 1997). In the present work, $\mathrm{E}$ value $(0.9129 \mathrm{KJ}$ mol-1) which is less than $8 \mathrm{KJ}$ mol-1, the biosorption of chromium (VI) ions onto citric acid modified tamarind pod shell (Tamarindus indica L.) is of physical in nature (Sawalha et al., 2006).

\section{Temkin adsorption isotherm (Temkin and Pyzhev,} 1940):

Linearized Temkin adsorption isotherm is given by the equation;

$$
q_{e}=\frac{R T}{b_{T}} \ln A_{T}+\frac{R T}{b_{T}} \ln C_{e}
$$

Where $b_{T}$ is the Temkin constant related to heat of biosorption $(\mathrm{J} / \mathrm{mol})$ and $A_{T}$ is the Temkin isotherm constant $(\mathrm{L} / \mathrm{g})$. Equilibrium data for the adsorption is plotted as $\mathrm{q}_{\mathrm{e}} \mathrm{vs} \operatorname{lnC}_{\mathrm{e}}$, as shown in Figure $10(\mathrm{~d})$. The two constants $b_{T}$ and $A_{T}$ are calculated from the slope $\left(\mathrm{R}_{\mathrm{T}} / \mathrm{b}_{\mathrm{T}}\right)$ and intercept $\left(\mathrm{R}_{\mathrm{T}} / \mathrm{b}_{\mathrm{T}} \cdot \ln \mathrm{A}_{\mathrm{T}}\right)$ of the line. The values of $A_{T}, b_{T}$ and regression coefficient $\left(R^{2}\right)$. The various constants and regression coefficient $R^{2}$ obtained from adsorption isotherms (Langmuir, Freundlich, Dubinin-Kaganer-Redushkevich (DKR) and Temkin) are summarized in Table 1.

Table 1: Adsorption isotherm constants for chromium (VI) bisorption by citric acid modified tamarind pod shell (Tamarindus indica $L$.)

\begin{tabular}{|c|c|c|c|c|c|c|c|c|c|c|c|c|}
\hline \multicolumn{4}{|c|}{ Langmuir parameters } & \multicolumn{3}{c|}{ Freundlich } & \multicolumn{4}{c|}{ DKR parameters } & \multicolumn{3}{c|}{ Temkin parameters } \\
\hline $\mathrm{q}_{\mathrm{m}}$ & $b$ & $R^{2}$ & $K$ & $1 / n$ & $R^{2}$ & $\beta$ & $q_{m}$ & $E$ & $R^{2}$ & $A_{T}$ & $b_{T}$ & $R^{2}$ \\
\hline $\begin{array}{c}43.85 \\
9\end{array}$ & $\begin{array}{c}0.063 \\
4\end{array}$ & $\begin{array}{c}0.996 \\
2\end{array}$ & $\begin{array}{c}2.772 \\
0\end{array}$ & $\begin{array}{c}0.705 \\
3\end{array}$ & $\begin{array}{c}0.989 \\
8\end{array}$ & $\begin{array}{c}6 \mathrm{E} \\
2\end{array}$ & $\begin{array}{c}23.159 \\
3\end{array}$ & $\begin{array}{c}0.912 \\
9\end{array}$ & $\begin{array}{c}0.713 \\
7\end{array}$ & $\begin{array}{c}0.896 \\
8\end{array}$ & $\begin{array}{c}253.45 \\
3\end{array}$ & $\begin{array}{c}0.903 \\
5\end{array}$ \\
\hline
\end{tabular}

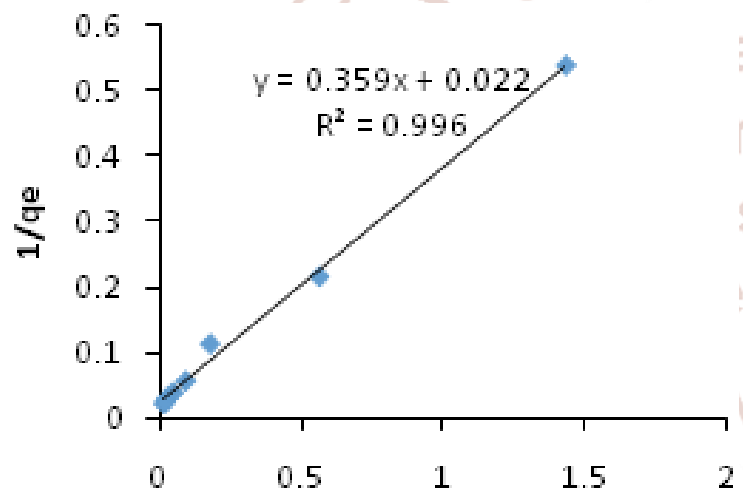

$1 / \mathrm{Ce}$

(a)

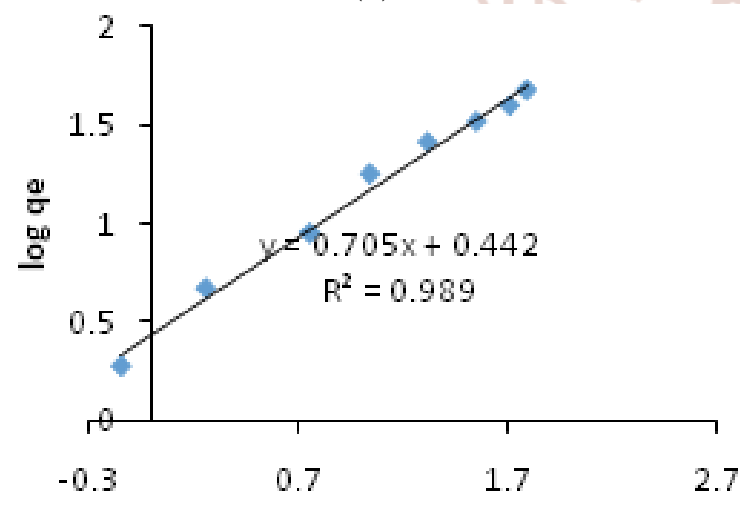

$\log \mathrm{Ce}$

(b)

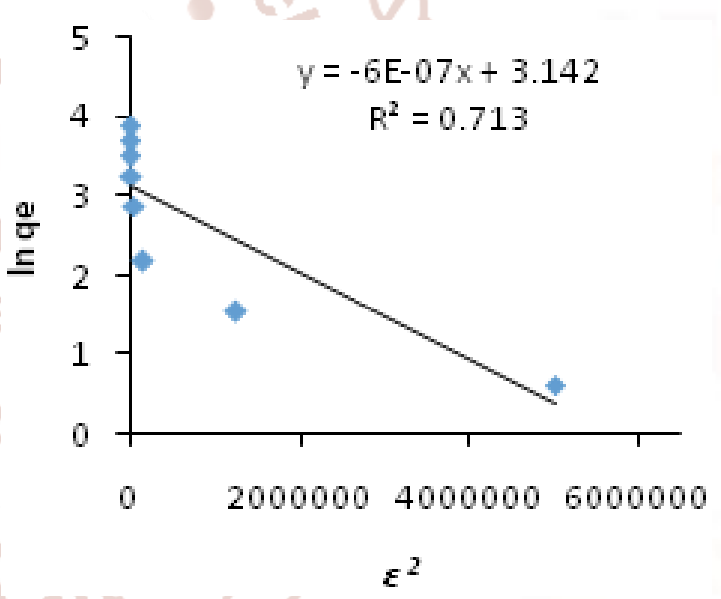

(c)

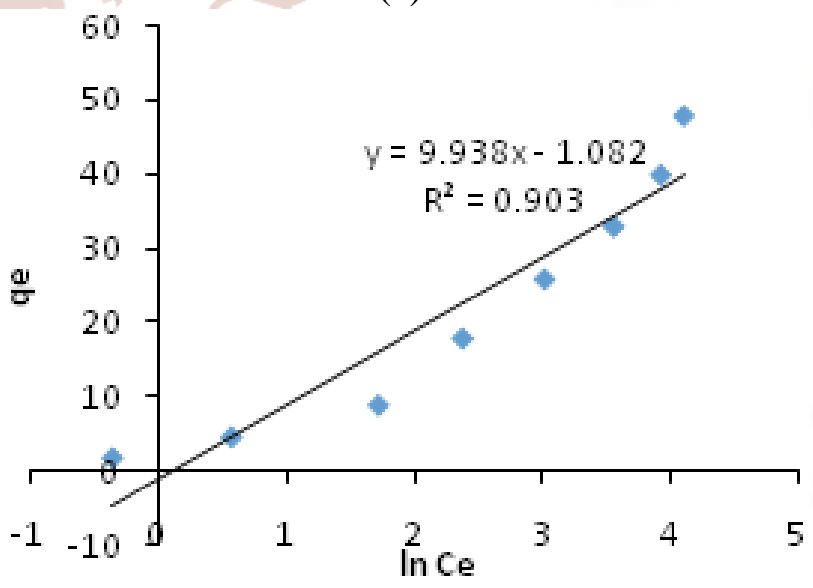

(d)

Figure 10: Adsorption isotherms (a) Langmuir, (b) Freundlich (c) DKR and (d) Temkin for chromium (VI) bisorption by citric acid modified tamarind pod shell (Tamarindus indica $L$.) (pH: 4.0, bio sorbent dose concentration: $5 \mathrm{~g} / \mathrm{L}$, contact time: 180 minutes, temperature: $40^{\circ} \mathrm{C}$ ) 


\section{Adsorption kinetic models:}

As aforementioned, a lumped analysis of adsorption rate is sufficient to partical operation from a system design point of view. The commonly employed lump kinetic models, namely (a) pseudo-first-order (b) pseudo-second-order (c) Elovich model (d) Weber \& Morris intra-particle diffusion model are presented below;

$$
\begin{aligned}
& \ln \left(q_{e}-q_{t}\right)=\ln q_{e}-k_{1} t \\
& \frac{t}{q_{t}}=\frac{1}{k_{2} q_{e}^{2}}+\frac{t}{q_{e}} \\
& q_{t}=\frac{1}{\beta} \ln (\alpha \beta)+\frac{1}{\beta} \ln t \\
& q_{t}=k_{i} t^{0.5}+c
\end{aligned}
$$

Where $q_{e}\left(\mathrm{mg} \mathrm{g}^{-1}\right)$ is the solid phase concentration at equilibrium, $q_{t}\left(\mathrm{mg} \mathrm{g}^{-1}\right)$ is the average solid phase concentration at time $\mathrm{t}(\mathrm{min}), k_{1}\left(\mathrm{~min}^{-1}\right)$ and $k_{2}\left(\mathrm{~g} \mathrm{mg}^{-1}\right.$ $\mathrm{min}^{-1}$ ) are the pseudo-first-order and pseudo-second order rate constants, respectively. The symbols of $\alpha$ $\left(\mathrm{mg} \mathrm{g}^{-1} \mathrm{~min}^{-1}\right)$ and $\beta\left(\mathrm{g} \mathrm{mg}^{-1}\right)$ are Elovich coefficients representing initial biosorption rate and desorption constants, respectively. $k i\left(\mathrm{mg} \mathrm{g}^{-1} \mathrm{~min}^{-1 / 2}\right)$ is the intraparticle diffusion rate constant, $\mathrm{c}$ is intercept.

If the adsorption follows the pseudo-first-order model, a plot of $\ln \left(\mathrm{q}_{\mathrm{e}}-\mathrm{q}_{\mathrm{t}}\right)$ against time $\mathrm{t}$ should be a straight line. Similarly, $\mathrm{t} / \mathrm{q}_{\mathrm{t}}$ should change lineally with time $\mathrm{t}$ if the adsorption process obeys the pseudo-second order model. If the adsorption process obeys Elovich model, a plot of $\mathrm{q}_{\mathrm{t}}$ against $\ln t$ should be a straight line. Also a plot of qt against t ${ }^{0.5}$ changes lineally the adsorption process obeys the Weber and Morris intraparticle diffusion model. Kinetic plots depicted in Figure 11 (a) (b) (c) and (d) (Septhumet al., 2007).

Biosorption of chromium (VI) onto bio sorbent was monitored at different specific time interval. The chromium (VI) uptake was calculated from the data obtained. From the chromium (VI) uptake was plotted against time to determine a suitable kinetic model, the adsorption data was fitted into pseudo-first-order model, pseudo-second-order model, Elovich models and the Weber \& Morris intra-particle diffusion model.

The pseudo-first-order model was plotted for $\ln \left(\mathrm{q}_{\mathrm{e}}-\mathrm{q}_{\mathrm{t}}\right)$ against $\mathrm{t}$ (Figure 11 (a)). The values of $\mathrm{k}_{1}$ and $\mathrm{q}_{\mathrm{e}}$ values were calculated from the slope $\left(\mathrm{k}_{1}\right)$ and intercept (ln $\mathrm{q}_{\mathrm{e}}$ ) of the plot and shown in Table 2. Pseudo-firstorder model showered the correlation value $\left(\mathrm{R}^{2}=\right.$ 0.8759 ) being lower than the correlation coefficient for the pseudo-second-order model. Kinetic biosorption for pseudo-first-order model occurs chemically and involves valency forces through ion sharing or exchange of electron between the bio sorbent and the ions adsorbed onto it (Septhum et al., 2007).

The pseudo-second-order model was plotted for $t / q_{t}$ against $\mathrm{t}$ (Figure $11(\mathrm{~b})$ ). The values of $\mathrm{q}_{\mathrm{e}}$ and $\mathrm{k}_{2}$ are calculated from the slope $\left(1 / \mathrm{q}_{\mathrm{e}}\right)$ and intercept $\left(1 / \mathrm{k}_{2}\right.$ $\mathrm{qe}^{2}$ ) of the plot and values are shown in Table 2. Pseudo-second-order kinetic model showered the strongest correlation $\left(R^{2}=0.9939\right)$. This suggests that chromium (VI) biosorption occurs in a monolayer fashion and which relies on the assumption that chemisorption or chemical adsorption is the rate limiting step. Chromium (VI) reacts chemically with the specific binding sites on the surface of bio sorbent.

The Elovich model was plotted for qt against $\ln t$ (Figure $11(\mathrm{c})$ ). The values of $\beta$ and $\alpha$ are calculated from the slope $(1 / \beta)$ and the intercept $(\ln (\alpha \beta) / \beta)$ of the plot and values are shown in Table 2. The Elovich model has been used with the assumption that the actual adsorption surface is energetically heterogeneous (Thomas and Thomas, 1997).

The Weber \& Morris intra-particle diffusion model was plotted for $\mathrm{q}_{\mathrm{t}}$ against $\mathrm{t}^{0.5}$ (Figure $11(\mathrm{~d})$ ). The value of $k i$ and $c$ are calculated from the slope $(k i)$ and intercept $(c)$ of the plot and values are shown in Table 2. The Weber and Morris intra-particle diffusion model showed a $\left(R^{2}=0.9417\right)$ being lower than the correlation coefficient for the pseudo-second-order model. The intercept of the plot does not pass through the origin, this is indicative of some degree of boundary layer control and intra-particle pore diffusion is not only rate-limiting step (Weber and Morris, 1963).

The plot of intra-particle diffusion model showed multilinearity, indicating that three steps take place. The first, sharper portion is attributed to the diffusion of adsorbate through the solution to the external surface of bio sorbent or the boundary layer diffusion of solute molecules. The second portion describes ion stage, where intra-particle diffusion is a rate limiting. The third portion is attributed to the final equilibrium stage. However the intercept of the line fails to pass through the origin which may attribute to the difference in the rate of mass transfer in the initial and final stages of biosorption (Panday et al., 1986). 
International Journal of Trend in Scientific Research and Development (IJTSRD) ISSN: 2456-6470

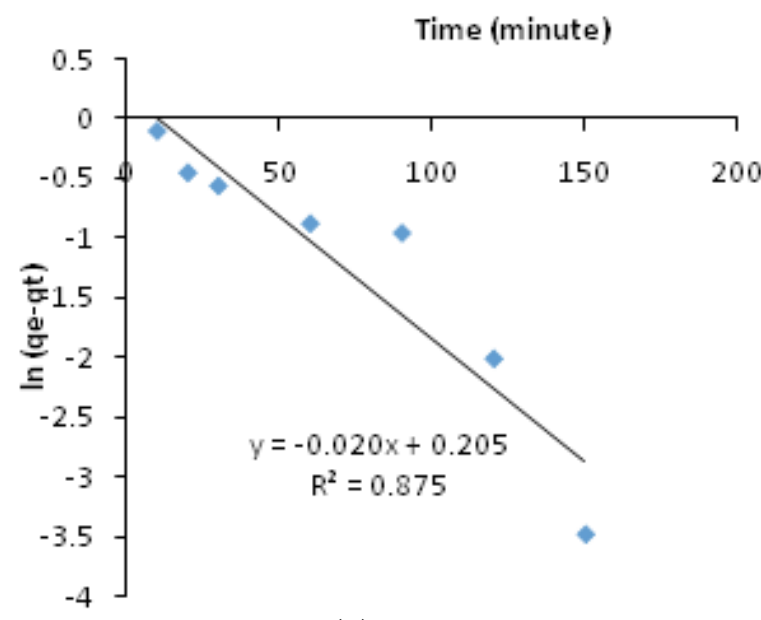

(a)

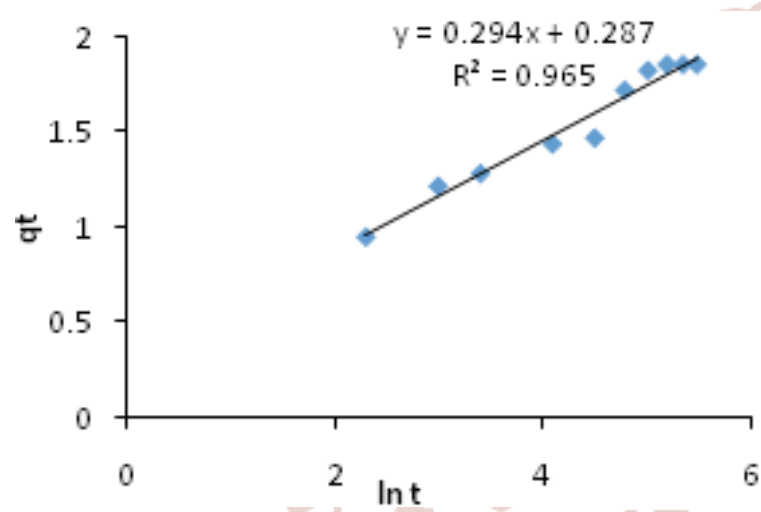

(c)

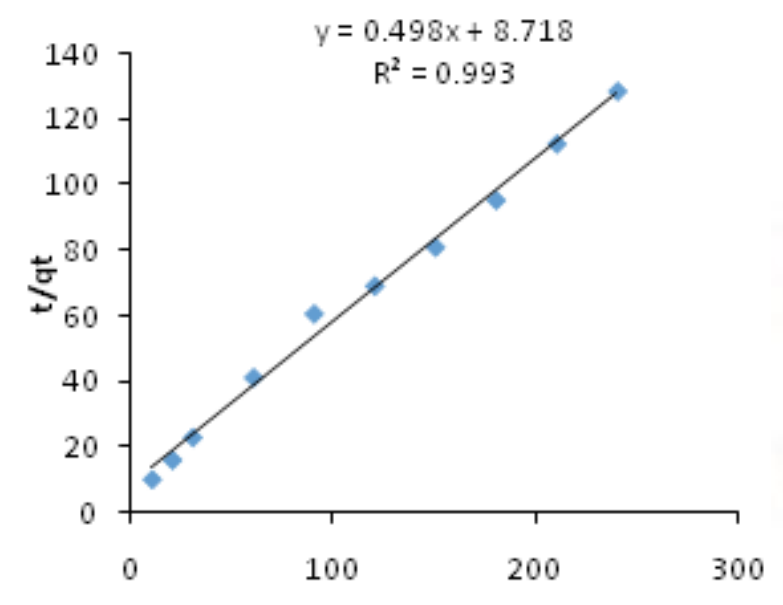

Time (minute)

(b)

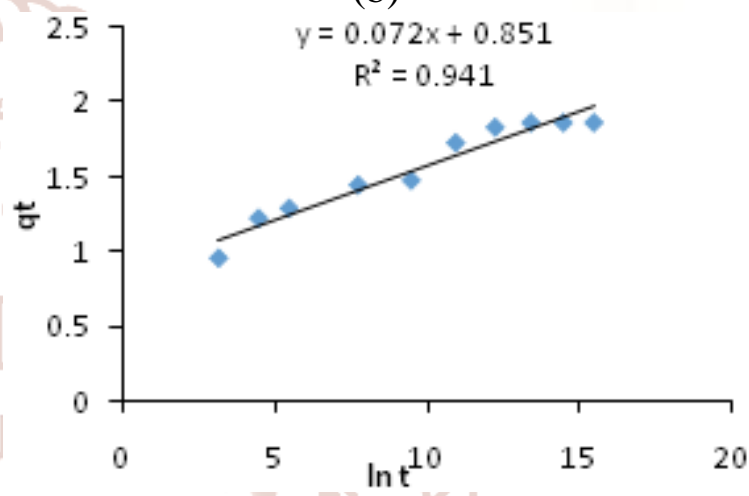

(d)

Figure 11: Adsorption kinetic models (a) pseudo-first-order, (b) pseudo-second-order (c) Elovich and (d) Weber and Morris intra-particle diffussion equation, for biosorption of chromium (VI) by citric acid modified tamarind pod shell (Tamarindus indica $L$.) (pH: 4.0, bio sorbent dose concentration: $5 \mathrm{~g} / \mathrm{L}$, initial chromium (VI) concentration: $10 \mathrm{mg} / \mathrm{L}$, temperature: $40^{\circ} \mathrm{C}$ )

Table2: Adsorption kinetic data for chromium (VI) biosorption by citric acid modified tamarind pod shell (Tamarindus indica L.)

\begin{tabular}{|c|c|c|c|c|c|c|c|c|c|c|c|}
\hline \multicolumn{3}{|c|}{$\begin{array}{c}\text { Pseudo-first-order } \\
\text { model }\end{array}$} & \multicolumn{3}{c|}{$\begin{array}{c}\text { Pseudo-second-order } \\
\text { model }\end{array}$} & \multicolumn{3}{c|}{ Elovich model } & \multicolumn{3}{c|}{ Intra-particle diffusion } \\
model
\end{tabular}

\section{Thermodynamic study}

The effect of temperature on removal of chromium (VI) from aqueous solutions in the concentration of chromium (VI) $10 \mathrm{mg} / \mathrm{L}$ and bio sorbent dose concentration $5 \mathrm{mg} / \mathrm{ml}$ with optimum $\mathrm{pH} 4.0$ was studied. Experiments were carried out at different temperatures from $20^{\circ} \mathrm{C}-40^{\circ} \mathrm{C}$. The samples were allowed to attain equilibrium. Sorption slightly increases from. The equilibrium constant (Catena and Bright, 1989) at various temperatures and thermodynamic parameters of adsorption can be evaluated from the following equations;

$$
\begin{aligned}
& K_{c}=\frac{C_{A e}}{C_{e}} \\
& \Delta G^{0}=-R T \ln K_{c}
\end{aligned}
$$

$$
\begin{gathered}
\Delta G^{0}=\Delta H^{0}-T \Delta S^{0} \\
\ln K_{c}=\frac{\Delta S^{0}}{R}-\frac{\Delta H^{0}}{R T}
\end{gathered}
$$

Where $K c$ is the equilibrium constant, $C e$ is the equilibrium concentration in solution $(\mathrm{mg} / \mathrm{L})$ and $C A e$ is the amount of chromium (VI) biosorbed on the bio sorbent per liter of solution at equilibrium $(\mathrm{mg} / \mathrm{L})$. $\Delta \mathrm{G}^{0}, \Delta \mathrm{H}^{0}$ and $\Delta \mathrm{S}^{0}$ are changes in standard Gibbs free energy $(\mathrm{kJ} / \mathrm{mol})$, standard enthalpy $(\mathrm{kJ} / \mathrm{mol})$ and standard entropy $(\mathrm{J} / \mathrm{mol} \mathrm{K})$, respectively. $\mathrm{R}$ is the gas constant $(8.314 \mathrm{~J} / \mathrm{mol} \mathrm{K})$ and $\mathrm{T}$ is the temperature $(\mathrm{K})$. 
The values of $\Delta \mathrm{H}^{0}$ and $\Delta \mathrm{S}^{0}$ were determined from the slope and the intercept from the plot of $\ln K c$ versus 1/T (Figure 12). The values of equilibrium constant $(K c)$, standard Gibbs free energy change $\left(\Delta \mathrm{G}^{0}\right)$, standard enthalpy change $\left(\Delta \mathrm{H}^{0}\right)$ and the standard entropy change $\left(\Delta \mathrm{S}^{0}\right)$ calculated in this work were presented in Table 3. The equilibrium constant $(K c)$ increases with increase in temperature, which may be attributed to the increase in the pore size and enhanced rate of intra-particle diffusion. The value of standard Gibbs free energy change $\left(\Delta G^{0}\right)$ is small and

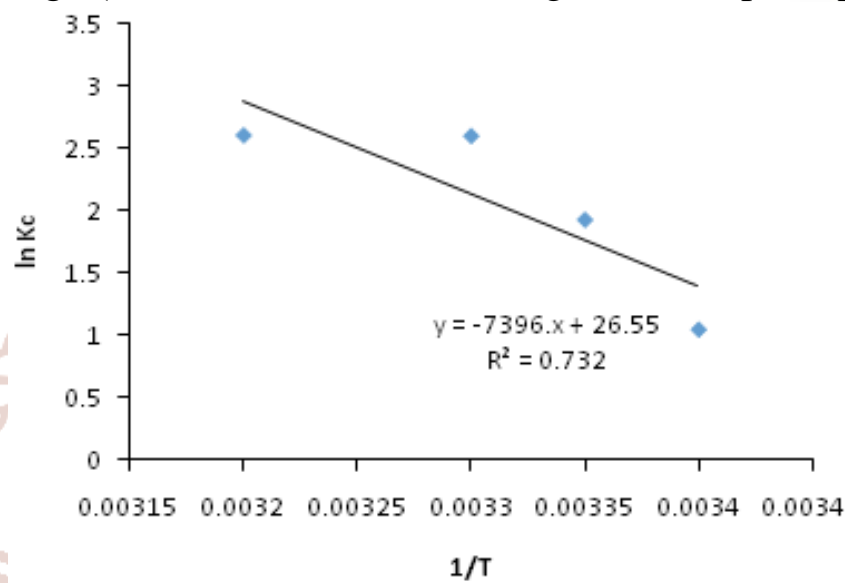

$1 / \mathrm{T}$ negative and indicates the spontaneous nature of the biosorption. The values of $\Delta \mathrm{G}^{0}$ were found to decreases as the temperature increases, indicating more driving force and hence resulting in higher biosorption capacity. The value of $\Delta \mathrm{H}^{0}$ was positive, indicating the endothermic nature of the biosorption of chromium (VI) onto citric acid modified tamarind pod shell (Tamarindus indica $L$.). The positive values of $\Delta S^{0}$ shows an affinity of bio sorbent and the increasing randomness at the solid solution interface during the biosorption process.

Figure 12: Plot of InKc against 1/T for determination of thermodynamic parameters for chromium (VI) biosorption by citric acid modified tamarind pod shell (Tamarindus indica $L$.) (pH: 4.0, bio sorbent dose concentration: $5 \mathrm{~g} / \mathrm{L}$, chromium (VI) concentration: $10 \mathrm{mg} / \mathrm{L}$, contact time: 180 minutes)

Table 3: Thermodynamic parameters of chromium (VI) biosorption by citric acid modified tamarind pod shell (Tamarindus indica $\mathrm{L}$.)

\begin{tabular}{|c|c|c|c|c|c|c|}
\hline Sr. No. & Temperature $\left(\mathrm{C}^{0}\right)$ & Temperature (K) & Kc & $\begin{array}{c}-\Delta \mathbf{G}^{0} \\
(\mathbf{K J} / \mathrm{mol})\end{array}$ & $\begin{array}{c}\Delta \mathbf{H}^{0} \\
(\mathrm{KJ} / \mathrm{mol})\end{array}$ & $\underset{(\mathrm{J} / \mathrm{mol})}{\Delta \mathbf{S}^{0}}$ \\
\hline 1 & $20^{\circ} \mathrm{C}$ & 293 & 2.8729 & 2.570 & \multirow{4}{*}{61.495} & \multirow{4}{*}{220.778} \\
\hline 2 & $25^{\circ} \mathrm{C}$ & 298 & 6.9365 & 4.798 & & \\
\hline 3 & $30^{\circ} \mathrm{C}$ & 303 & 13.5985 & 6.574 & & \\
\hline 4 & $40^{\circ} \mathrm{C}$ & $313=$ & 13.6627 & 6.803 & & \\
\hline
\end{tabular}

\section{Conclusions}

Biosorption is a relatively new process that has shown significant contribution for the removal of contaminants from aqueous effluents. In this study, the toxic chromium (VI) biosorption on inexpensive and efficient bio sorbents from agricultural waste materials have been investigated as replacement strategy for existing conventional systems. The use of these low cost bio sorbents is recommended since they are relatively cheap or of no cost, easily available, renewable and show highly affinity for $\mathrm{Cr}$ (VI) ions. Literature also reveals that in some cases the modification of the adsorbent increased the removal efficiency. Citric acid modified tamarind pod shell powder is effective in removal of $\mathrm{Cr}$ (VI) ion from aqueous solutions. Adsorption of $\mathrm{Cr}(\mathrm{VI})$ is dependent on its initial concentration of $\mathrm{Cr}$ (VI) and $\mathrm{pH}$ of the solution. The results indicate that the optimum $\mathrm{pH}$ for the removal of $\mathrm{Cr}(\mathrm{VI})$ ions by citric acid modified tamarind pod shell is around 4. Chromium (VI) removal is built up; equilibrium conditions are attained after nearly $180 \mathrm{~min}$. Isothermal data of $\mathrm{Cr}$ (VI) sorption on citric acid modified tamarind pod shell can be modeled by Langmuir isotherm. Kinetic study revealed that the biosorption process followed pseudo second order kinetics. Thermodynamics study indicated spontaneous and endothermic process with increase of degree of randomness. 


\section{References:}

1. Ahalya N., Kanamadi R D and Ramachandra T V., (2008) Biosorption of Chromium (VI) by Tamarindus indica pod shells, Journal of Environmental Science Research International, vol.1(2), pp.77-81.

2. Altun T, Pehlivan E. (2012) Removal of cr (VI) from aqueous solutions by modified walnut shells. Food Chem, vol, 132(2), pp.693-700.

3. Basal M, Singh D, Garg V (2009) A comparative study for the removal of hexavalent chromium from aqueous solution by agriculture wastes' carbons. J Hazard Mater vol. 171, pp. 83-92.

4. Catena G. C. and Bright F. V., (1989).Thermodynamic study on the effect of cyclodixtrin inclusion with aniline naphthalene sulphonates. Anal. Chem., 61, 905-909.

5. Chowdhury Z. Z., S. M. Zain and A. K. Rashid (2011) Equilibrium Isotherm Modeling, Kinetics and Thermodynamics Study for removal of Lead from Waste Water. E-Journal of Chemistry, vol. 8(1), pp. 333-339.

6. Dakiky M, Khamis M, Manassra A, Mer'eb M (2002) Selective adsorption of chromium VI in industrial wastewater using low cost abundantly available adsorbents. AdvEnvironm Res, vol. 6, pp. 533-40.

7. Dubinin, M. M. and Radushkevich, L. V., 1947. Equation of the characteristic curve of activated charcoal, Proc. Academy of Sci. Phy. Chem. Section, U.S.S.R. 55, 331-333.

8. Erol Pehlivan, Huseyin Deveci (2015). Removal of $\mathrm{Cr}$ (VI) Ion by Modified Bean Husk. Faculty of Engineering-Architecture, pp. 294-300.

9. Freundlich, H. M. F., (1906). Uber dies adsorption in losungen, Zeitschriftfue Physikalische Chemie (Leipzig). A57, 385-470.

10. Gao, K., Pearce, J., Jones, J. \& Taylor, C. (1999) Interaction between peat, humic acid and aqueous metal ions, Environ. Geo. Health. Vol. 21, pp.1326.

11. GodeaFethiye, Elif Dincturk Atalaya, Erol Pehlivanb (2008) Removal of $\mathrm{Cr}$ (VI) from aqueous solutions using modified red pine sawdust. Journal of Hazardous Materials, vol. 152, pp. 1201-1207.
12. Gupta V, Rastogi A (2009) Biosorption of hexavalent chromium by raw and acid treated green algae Oedogoniumhatei from aqueous solutions. J Hazard Mater, vol. 163, pp. 396-402.

13. Gupta V K, Ali L. (2004) Removal of lead and chromium from wastewater using bagasse fly asha sugar industry waste. J Coll Interf Sci, vol. 2, pp. $321-28$.

14. Gupta V K, Rastogi A. (2008) Biosorption of lead (II) from aqueous solutions by non-living algal biomass Oedogonium sp. and Nostoc sp.-a comparative study. J Hazardous Mater, vol. 152, pp. 407-14.

15. Gupta V K, Rastogi A. (2008) Biosorption of lead from aqueous solutions by green algae Spirogyra species: kinetics and equilibrium studies. J Hazardous Mater, vol.1, pp. 407-14.

16. Gupta V K, Rastogi A. (2008) Sorption and desorption studies of chromium (VI) from nonviable cyanobacterium Nostocmuscorum biomass. J Hazardous Mater, vol.154, pp.347-54.

17. Hu, Z., Lei, L., Li, Y. \& Ni, Y. (2003) Chromium adsorption on high-performance activated carbons from aqueous solution, Sep. Purif.Technol. vol.31, pp. $13-18$.

18. Jain Anand P. (2015). Investigation \&Comparative Study of Effectiveness of Adsorbent Synthesized from 'Tectonagrandis' seed in removal of $\mathrm{Cr}$ (VI) from aqueous solution. Int. Journal of Engineering Research and Applications. Vol. 5, pp. 116-120.

19. Joelington do C. Conceicao, Victor Hugo S. Ramos, Edilson de Jesus, Antônio Santos Silva and Antonio Wilson M. de C. Costa (2014) Biosortion of $\mathrm{Cr}$ (VI) from Aqueous Solutions Using Chemically Modified Okra Powder. Journal of Basic \& Applied Sciences, vol. 10, pp.73-79.

20. Kandah MuntherIssa, Mamdouh A. Allawzi and Hussein Allaboun (2008) Improvement of Manure Adsorption Capacity for Cobalt Removal by Chemical Treatment with Citric Acid. Jordan Journal of Civil Engineering, Vol.2 (4), pp. 344354.

21. Karthikeyan S., Balasubramanian R. and Iyer C. S. P., 2007.Evaluation of marine algae Uivafasciata and Sargassum sp. for biosorption of $\mathrm{Cu}$ (II) from aqueous solutions. Bioresour. Technol., 98 (2), 452-455. 
International Journal of Trend in Scientific Research and Development (IJTSRD) ISSN: 2456-6470

22. Khezami, L. \& Capart, R. (2005) Removal of chromium (VI) from aqueous solution by activated carbons: Kinetic and equilibrium studies, J. Hazard. Mater. B. vol. 123: pp. 223-231.

23. Kocaoba, S. \& Akcin, G. (2005) Removal of chromium (III) and cadmium (II) from aqueous solutions, Desalination. vol.180, (13), pp. 151156.

24. Langmuir, I., 1918. The adsorption of gases on plane surface of glass, mica and platinum, J. Am. Chem. Soc. 40, 1361-1403.

25. Lee S H, Park C-H. (2012) Biosorption of Heavy Metal Ions by Brown Seaweeds from Southern Coast of Korea, Biotechnol. Bioproc Eng, vol. 17, pp. 853-61.

26. Naiya T. K., Das S. K. and Bhattacharya A. K., (2009). Adsorption of $\mathrm{Cd}$ (II) $\& \mathrm{~Pb}$ (II) from aqueous solution on activated alumina. J. Coll. Inter. Sci., 21, 434-451.

27. Olivieri N. F. and Brittenham G. M., (1997). Ironchelating therapy and the treatment of thalassemia. Blood, 89, 739-761.

28. Pakade Vusumzi Emmanuel, Themba Dominic Ntuli, Augustine Enakpodia of omaja (2017) Biosorption of hexavalent chromium from aqueous solutions by Macadamia nutshell powder. Appl Water Sci, vol. 7, pp. 3015-3030.

29. Panday K. K., Prasad G. and Singh V. N., (1986).Mixed adsorbents for Cu (II) removal from aqueous solutions. Environ. Technol. Lett., 50, 547-550.

30. Parlayici-Karata and E. Pehlivan (2012) Removal of hexavalent chromium using modified pistachio shell. Advances in Environmental Research, Vol. 1(2), pp.167-179.

31. Pehlivan E, Pehlivan E, Kahraman H T. (2012) Hexavalent chromium removal by Osage Orange. Food Chem, vol. 133, pp. 1478-84.

32. Petruzzelli, D., Passino, J. R. \&Tiravantit, G. (1996) Ion exchange process for chromium removal and recovery from tannery wastes, Ind. Eng. Chem. Res., vol. 34(8), pp.2612-2617.

33. Rajeshwari M, Pushpa A, Priya S P, Sandhya G R, Pavithra G M. (2013) Continuous Biosorption of
Cadmium by Moringaoleifera in a Packed Column. J Biotechnol Bioproc Eng, vol. 18(2), pp. 321-25.

34. Rao P. S., Shashikant R. and Munjunatha G. S., 1992. Kinetic studies on adsorption of chromium by coconut shell carbons from synthetic effluents. J. Environ. Sci. Health, 27, 2227-2241.

35. Sawalha, M. F. and Peralta-Videa, J. R., Romero Gonzalez, J. and Gardea-Torresdey, J. L., (2006). Biosorption of $\mathrm{Cd}$ (II), Cr (III) and $\mathrm{Cr}$ (VI) by saltbush (Atriplexcanescens) biomass: Thermodynamic and isotherm studies, J. Colloid Interface Sci., 300, 100-104.

36. Septhum, C., Rattanaphani, S., Bremner, J. B. and Rattanaphani, V., 2007.An adsorption of Al (III) ions onto chitosan. J. Hazardous Materials. 148, 185-191.

37. Seshadri N., B. Ramesh Naik, N. V. Sandeep Kumar, D. K. Venkata Ramana, K. Seshaiah (2014) Application of Citric Acid Modified Annona squamosa (Custard Apple) Bark Powder as Bio sorbent to Remove Ni (II) From Waste Water. Indian Journal of Advances in Chemical Science, vol. 3, pp. 1-10.

38. Sharma Parul, Pritee Goyal \& Shalini Srivastava (2007) Biosorption of trivalent and hexavalent chromium from aqueous systems using shelled Moringaoleifera seeds, Chemical Speciation \& Bioavailability, vol. 9(4), pp.175-182.

39. Shartooh S. M., M. N. A. Al-Azzawi, S. A. K. AlHiyaly (2013) Pomegranate Peels as Bio sorbent Material to Remove Heavy Metal Ions from Industerial Wastewater. Iraqi Journal of Science, Vol 54(4), pp: 823-831.

40. Temkin, M. J. and Pyzhev, V., (1940). Kinetics of ammonia synthesis on promoted iron catalysts. Acta Physiochim. Urrs. 12, 217-222.

41. Thomas, J. M. And Thomas, W. J., (1997). Principle and Practice of heterogeneous catalysis, weinheim, VCH.

42. Weber, W. J. and Morris, J. C., 1963.Kinetics of adsorption on carbon solution. J. Sanit. Eng. Div. Am. Soc. Civ. Engg. 89, 31-59. 